Article

\title{
Solubilization, Hansen Solubility Parameters, Solution Thermodynamics and Solvation Behavior of Flufenamic Acid in (Carbitol + Water) Mixtures
}

\author{
Faiyaz Shakeel ${ }^{(D)}$ and Sultan Alshehri * (D) \\ Department of Pharmaceutics, College of Pharmacy, King Saud University, Riyadh 11451, Saudi Arabia; \\ faiyazs@fastmail.fm \\ * Correspondence: salshehri1@ksu.edu.sa
}

Received: 29 August 2020; Accepted: 21 September 2020; Published: 23 September 2020

\begin{abstract}
The solubilization, solution thermodynamics, solvation behavior and Hansen solubility parameters (HSPs) of an anti-inflammatory medicine flufenamic acid (FFA) in various Carbitol + water mixtures were evaluated in this study. The experimental solubility of FFA in mole fraction $\left(x_{\mathrm{e}}\right)$ was measured at $T=298.2-318.2 \mathrm{~K}$ and $p=0.1 \mathrm{MPa}$ using a static equilibrium method. The $x_{\mathrm{e}}$ values of FFA in various Carbitol + water mixtures were correlated with van't Hoff, Apelblat, Yalkowsky-Roseman, Jouyban-Acree and Jouyban-Acree-van't Hoff models. All the studied models showed good correlation with mean error values of less than $2 \%$. The $x_{\mathrm{e}}$ value of FFA was found to increase significantly with the increase in temperature and Carbitol mass fraction in all Carbitol + water mixtures evaluated. The maximum and minimum $x_{\mathrm{e}}$ values of FFA were recorded in pure Carbitol $\left(2.81 \times 10^{-1}\right)$ at $T=318.2 \mathrm{~K}$ and pure water $\left(5.80 \times 10^{-7}\right)$ at $T=298.2 \mathrm{~K}$, respectively. Moreover, the HSP of FFA was found to be more closed with that of pure Carbitol, indicating the maximum solubility of FFA in pure Carbitol. The estimated values of activity coefficients showed higher molecular interactions in FFA-Carbitol combinations compared with FFA-water combinations. Thermodynamic studies indicated an endothermic and entropy-driven dissolution of FFA in all Carbitol + water mixtures. The solvation behavior of FFA was observed as enthalpy driven in all Carbitol + water combinations evaluated.
\end{abstract}

Keywords: carbitol; cosolvent mixtures; flufenamic acid; solubility; solution thermodynamics

\section{Introduction}

Flufenamic acid (FFA; Figure 1) is a small molecule non-steroidal anti-inflammatory drug (NSAID) which is used in the treatment of pain and inflammation associated with different diseases [1,2]. It is available in oral and topical dosage forms on the market $[2,3]$. It is a potent NSAID and has a pK value of 3.9, with a high octanol/water partition coefficient $(\log \mathrm{P}=4.88)$ [3].<smiles>O=C(O)c1ccccc1Nc1cccc(C(F)(F)F)c1</smiles>

Figure 1. Molecular structure of flufenamic acid (FFA). 
FFA is practically insoluble in an aqueous media such as water. Hence, its dosage form design, especially in terms of liquid dosage forms, such as syrups and injections, is difficult [4]. Various methods of solubility enhancement have been reported in literature [5-7]. However, the cosolvency method of solubility enhancement is the simplest and most convenient [5]. The solubility values, solubility parameters and other physicochemical characteristics of drugs in cosolvent-water mixtures are important for drug discovery research and dosage form development [6-8]. Hence, this physicochemical behavior of FFA in cosolvent-water combinations must be investigated in order to get its proper physicochemical data [8]. The commonly used cosolvents for solubility enhancement are ethanol, propylene glycol and polyethylene glycol 400 (PEG 400) [6,9]. However, Carbitol [also known as Transcutol or 2-(2-ethoxyethoxy) ethanol] has also been reported as a potent cosolvent in the solubility enhancement of various poorly-soluble drugs in addition to its complete miscibility with water [10-12]. The efficiency of Carbitol had been investigated in the solubilization of different, poorly water-soluble compounds in literature [10-15]. The solubility of FFA in water, light mineral oil and polyethylene glycol 400 (PEG 400) at $T=295.2 \mathrm{~K}, T=305.2 \mathrm{~K}$ and $T=298.2 \mathrm{~K}$, respectively, has been reported elsewhere [3,16-18]. The solubility of FFA in some organic solvents like hexane, methyl benzene and ethanol at $T=298.2 \mathrm{~K}$ has also been reported [19]. Temperature-dependent solubility values of FFA in hexane and 1-octanol at $T=293.2-315.2 \mathrm{~K}$ was also reported $[2,20]$. Some researchers also reported the temperature-dependent solubility values of FFA in ethanol and 1-octanol at $T=298.8-322.3 \mathrm{~K}$ [21]. Temperature-dependent solubility values of FFA in eleven different pure solvents, including water, methanol, ethanol, isopropanol, 1-butanol, 2-butanol, ethylene glycol, propylene glycol, PEG 400, Carbitol and dimethyl sulfoxide at $T=298.2-318.2 \mathrm{~K}$ was also reported elsewhere [4]. However, the solubility values of FFA in different Carbitol + water mixtures have not been studied and reported so far. Therefore, solubilization, Hansen solubility parameters, solvation behavior and solution thermodynamics of FFA in various Carbitol + water mixtures, including pure solvents (Carbitol and water), at $T=298.2-318.2 \mathrm{~K}$ and $p=0.1 \mathrm{MPa}$, were evaluated and reported in this work. The obtained solubility values of FFA were correlated using van't Hoff, Apelblat, Yalkowsky-Roseman, Jouyban-Acree and Jouyban-Acree-van't Hoff models. The solubility values and physicochemical data of FFA reported in this research could be applicable in the drug discovery process and dosage form design of FFA.

\section{Materials and Methods}

\subsection{Materials}

FFA was procured from Sigma-Aldrich (St. Louis, MO, USA). Carbitol was obtained from Gattefossé (Lyon, France). The deionized/chromatography-grade water was obtained from a Milli-Q water purification unit. The details of the materials are presented in Table 1.

Table 1. A sample table for materials.

\begin{tabular}{|c|c|c|c|c|c|c|c|}
\hline Material & $\begin{array}{l}\text { Molecular } \\
\text { Formula }\end{array}$ & $\begin{array}{c}\text { Molar Mass } \\
\left(\mathrm{g} \mathrm{mol}^{-1}\right)\end{array}$ & $\begin{array}{c}\text { CAS Registry } \\
\text { No. }\end{array}$ & $\begin{array}{l}\text { Purification } \\
\text { Method }\end{array}$ & $\begin{array}{c}\text { Mass Fraction } \\
\text { Purity }\end{array}$ & $\begin{array}{c}\text { Analysis } \\
\text { Method }\end{array}$ & Source \\
\hline FFA & $\mathrm{C}_{14} \mathrm{H}_{10} \mathrm{~F}_{3} \mathrm{NO}_{2}$ & 281.23 & $530-78-9$ & None & $>0.97$ & HPLC & Sigma-Aldrich \\
\hline Carbitol & $\mathrm{C}_{6} \mathrm{H}_{14} \mathrm{O}_{3}$ & 134.17 & $111-90-0$ & None & $>0.99$ & GC & Gattefossé \\
\hline Water & $\mathrm{H}_{2} \mathrm{O}$ & 18.07 & $7732-18-5$ & None & - & - & Milli-Q \\
\hline
\end{tabular}

The purity and analysis methods were obtained directly from the supplier; FFA: flufenamic acid; HPLC: high-performance liquid chromatography; GC: gas chromatography.

\subsection{Solvent Mixture Preparations}

All Carbitol + water mixtures were prepared by mass, using an OHAUS Pioneer (Parsippany, NJ, USA) analytical balance with sensitivity of $\pm 0.10 \mathrm{mg}$. The mass fraction of Carbitol for different binary mixtures was prepared by varying 0.10 from $0.10-0.90$. 


\subsection{FFA Solubility Determination}

The solubility of FFA in various Carbitol + water mixtures $(m=0.1-0.9 ; m$ is the mass fraction of Carbitol in mixed solvent systems), including pure water $(m=0.0)$ and pure Carbitol $(m=1.0)$, was determined at $T=298.2-318.2 \mathrm{~K}$ and $p=0.1 \mathrm{MPa}$, using a static equilibrium method [22]. Prior to the solubility determination of FFA, the reliability of the experimental technique was verified by measuring the solubility of sodium chloride in neat water at $T=298.15$ and $T=323.15 \mathrm{~K}$. The solubility of sodium chloride in neat water was also compared with its reported values [23]. For the solubility determination of FFA, the excess amount of FFA was dispensed in known amounts of various mixed solvents, including pure water and pure Carbitol. Each procedure was carried out in three replicates $(n=3)$. The obtained mixtures were sonicated for about $10 \mathrm{~min}$ and kept in a WiseBath ${ }^{\circledR}$ WSB Shaking Water Bath (model WSB-18/30/-45, Daihan Scientific Co. Ltd., Seoul, Korea) for equilibrium. Each sample in the shaker was rotated at $100 \mathrm{rpm}$ for a period of $72 \mathrm{~h}$ [4]. After saturation, each sample was withdrawn carefully and centrifuged at $5000 \mathrm{rpm}$ for $30 \mathrm{~min}$. The supernatant from each sample was taken and utilized for the estimation of FFA content using a high-performance liquid chromatography technique at $245 \mathrm{~nm}$ [4]. The binary combination of methanol and ethanol $(80: 20 \%, v / v)$ was utilized as the mobile phase for FFA estimation. The solubility of FFA in the mole fraction $\left(x_{\mathrm{e}}\right)$ was determined using its standard formulate, described previously $[12,13]$.

\subsection{Hansen Solubility Parameters (HSPs) of FFA and Pure Solvents}

The HSP of drug molecules is related to its solubility in neat solvent or cosolvent-water mixtures. It has been reported that the closed HSP value of drug molecules with that of a particular solvent could result in the maximum solubility of the drug molecule in that particular solvent [24]. Therefore, HSP for FFA, neat Carbitol and neat water were estimated in this work. The total HSP $\left(\delta_{t}\right)$ value for FFA, pure Carbitol and pure water was estimated using the following equation [25-28]:

$$
\delta_{t}^{2}=\delta_{d}^{2}+\delta_{p}^{2}+\delta_{h}^{2}
$$

where $\delta_{t}=$ total HSP, $\delta_{d}=$ dispersion HSP, $\delta_{p}=$ polar HSP and $\delta_{h}=$ hydrogen-bonded HSP. These values for FFA and pure solvents were estimated using HSPiP software (version 4.1.07, Louisville, KY, USA) by putting the simplified molecular-input line-entry system (SMILES) of each component into the software [26].

\subsection{Solute-Solvent Interactions and Determination of Ideal Solubility and Activity Coefficients}

The ideal solubility $\left(x^{i d l}\right)$ of FFA at $T=298.2-318.2 \mathrm{~K}$ was obtained using the following equation [29]:

$$
\ln x^{i d l}=\frac{-\Delta H_{f u s}\left(T_{f u s}-T\right)}{R T_{f u s} T}+\left(\frac{\Delta C_{p}}{R}\right)\left[\frac{T_{f u s}-T}{T}+\ln \left(\frac{T}{T_{f u s}}\right)\right]
$$

where $T_{\text {fus }}=$ fusion temperature of FFA, $R$ = universal gas constant, $\Delta H_{\text {fus }}=$ fusion enthalpy of FFA and $\Delta C_{p}=$ molar heat capacity different between the solid state and liquid state of FFA [29,30]. The values of $T_{\text {fus }}, \Delta H_{\text {fus }}$ and $\Delta C_{p}$ for FFA were taken as $407.77 \mathrm{~K}, 29.85 \mathrm{~kJ} \mathrm{~mol}^{-1}$ and $73.29 \mathrm{~J} \mathrm{~mol}^{-1} \mathrm{~K}^{-1}$, respectively, from reference [4].

The activity coefficient $\left(\gamma_{i}\right)$ for FFA in a mixed solvent system was calculated using the following equation $[29,31]$ :

$$
\gamma_{i}=\frac{x^{i d l}}{x_{e}}
$$

The solute-solvent interactions at the molecular level were explained based on the quantitative values of $\gamma_{i}$. 


\subsection{Apparent Thermodynamic Analysis of FFA Solution}

The dissolution characteristics of FFA in mixed solvent systems and pure solvents were investigated using apparent thermodynamic analysis with the help of van't Hoff and Gibbs equations. The van't Hoff equation was applied to determine apparent thermodynamic parameters of FFA in the mixed solvent system. The van't Hoff equation was recorded at the mean harmonic temperature $\left(T_{h m}\right)$ of $308 \mathrm{~K}$ at $T=298.2-318.2 \mathrm{~K}$, expressed using the following equation $[29,32]$ :

$$
\left(\frac{\partial \ln x_{e}}{\partial\left(\frac{1}{T}-\frac{1}{T_{h m}}\right)}\right)_{P}=-\frac{\Delta_{s o l} H^{0}}{R}
$$

where $\Delta_{\text {sol }} H^{0}=$ apparent standard enthalpy for FFA.

By making the graphs between $\ln x_{e}$ values of FFA and $\frac{1}{T}-\frac{1}{T_{h m}}$ (supplementary Figure S1), the $\Delta_{\text {sol }} H^{0}$ and apparent standard Gibbs energy $\left(\Delta_{s o l} G^{0}\right)$ values for FFA were calculated from the slope and intercept, respectively, by applying the following equations [33]:

$$
\begin{aligned}
& \Delta_{\text {sol }} H^{0}=-R\left(\frac{\partial \ln x_{e}}{\partial\left(\frac{1}{T}-\frac{1}{T_{h m}}\right)}\right)_{P} \\
& \Delta_{\text {sol }} G^{0}=-R T_{h m} \times \text { intercept }
\end{aligned}
$$

The apparent standard entropy $\left(\Delta_{\text {sol }} S^{0}\right)$ value for FFA in mixed solvent systems and pure solvents was calculated using the Gibbs equation, expressed as follows [29,32,33]:

$$
\Delta_{\text {sol }} S^{0}=\frac{\Delta_{\text {sol }} H^{0}-\Delta_{\text {sol }} G^{0}}{T_{h m}}
$$

\subsection{Enthalpy-Entropy Compensation Analysis}

The solvation behavior of FFA in mixed solvent systems and pure solvents was investigated using enthalpy-entropy compensation analysis [12,32]. Such analysis was carried out by plotting the weighted graphs of $\Delta_{\text {sol }} H^{\circ}$ vs. $\Delta_{\text {sol }} G^{\circ}$ at $T_{h m}=308 \mathrm{~K}$ [12].

\subsection{Computational Modeling}

The solubilities of FFA recorded in this work were regressed using various computational models like the van't Hoff, Apelblat, Yalkowsky-Roseman, Jouyban-Acree and Jouyban-Acree-van't Hoff models [34-40].

The van't Hoff model solubility $\left(x^{V a n^{\prime} t}\right)$ of FFA in mixed solvent systems and pure solvents was calculated using the following equation [34]:

$$
\ln x^{\operatorname{Van}^{\prime} t}=a+\frac{b}{T}
$$

where $a$ and $b=$ model coefficients of Equation (8) and the values of these model coefficients were obtained using the least square method. The correlation between the experimental and van't Hoff model solubilities of FFA was performed in terms of root mean square deviation (RMSD) and determination coefficient $\left(R^{2}\right)$. The RMSD was calculated using the following equation:

$$
R M S D=\left[\frac{1}{N} \sum_{i=1}^{N}\left(\frac{x_{c}-x_{e}}{x_{e}}\right)^{2}\right]^{\frac{1}{2}}
$$


where $N=$ number of experimental data points and $x_{c}=$ calculated solubility of the respective model. The Apelblat model solubility $\left(x^{A p l}\right)$ of FFA in mixed solvent systems, including pure solvents, was estimated using the following equation [35,36]:

$$
\ln x^{A p l}=A+\frac{B}{T}+C \ln (T)
$$

where $A, B$ and $C=$ model coefficients of Equation (10) and the values of these model coefficients were obtained by adopting a nonlinear multivariate regression analysis of experimental solubilities of FFA provided in Table 2 [34]. The correlation between the experimental and Apelblat model solubilities of FFA was also performed in terms of RMSD and $R^{2}$.

Table 2. Experimental mole fraction solubilities $\left(x_{e}\right)$ of flufenamic acid (FFA) in various Carbitol + water mixtures $(m)$ at $T=298.2-318.2 \mathrm{~K}$ and $p=0.1 \mathrm{MPa}{ }^{\text {a }}$.

\begin{tabular}{cccccc}
\hline \multirow{m}{*}{} & \multicolumn{5}{c}{$\boldsymbol{x}_{\boldsymbol{e}}$} \\
\cline { 2 - 6 } & $\boldsymbol{T}=\mathbf{2 9 8 . 2} \mathbf{K}$ & $\boldsymbol{T}=\mathbf{3 0 3 . 2 ~ K}$ & $\boldsymbol{T}=\mathbf{3 0 8 . 2 ~ K}$ & $\boldsymbol{T}=\mathbf{3 1 3 . 2 ~ K}$ & $\boldsymbol{T}=\mathbf{3 1 8 . 2 ~ K}$ \\
\hline 0 & $5.80 \times 10^{-7}$ & $8.01 \times 10^{-7}$ & $1.06 \times 10^{-6}$ & $1.32 \times 10^{-6}$ & $1.63 \times 10^{-6}$ \\
0.1 & $2.16 \times 10^{-6}$ & $2.83 \times 10^{-6}$ & $3.70 \times 10^{-6}$ & $4.54 \times 10^{-6}$ & $5.54 \times 10^{-6}$ \\
0.2 & $7.42 \times 10^{-6}$ & $9.76 \times 10^{-6}$ & $1.27 \times 10^{-5}$ & $1.53 \times 10^{-5}$ & $1.86 \times 10^{-5}$ \\
0.3 & $2.67 \times 10^{-5}$ & $3.43 \times 10^{-5}$ & $4.30 \times 10^{-5}$ & $5.11 \times 10^{-5}$ & $6.10 \times 10^{-5}$ \\
0.4 & $9.39 \times 10^{-5}$ & $1.22 \times 10^{-4}$ & $1.49 \times 10^{-4}$ & $1.76 \times 10^{-4}$ & $2.11 \times 10^{-4}$ \\
0.5 & $3.36 \times 10^{-4}$ & $4.12 \times 10^{-4}$ & $4.99 \times 10^{-4}$ & $5.84 \times 10^{-4}$ & $6.83 \times 10^{-4}$ \\
0.6 & $1.21 \times 10^{-3}$ & $1.43 \times 10^{-3}$ & $1.73 \times 10^{-3}$ & $1.99 \times 10^{-3}$ & $2.32 \times 10^{-3}$ \\
0.7 & $4.25 \times 10^{-3}$ & $4.95 \times 10^{-3}$ & $5.81 \times 10^{-3}$ & $6.62 \times 10^{-3}$ & $7.58 \times 10^{-3}$ \\
0.8 & $1.53 \times 10^{-2}$ & $1.73 \times 10^{-2}$ & $2.00 \times 10^{-2}$ & $2.24 \times 10^{-2}$ & $2.55 \times 10^{-2}$ \\
0.9 & $5.37 \times 10^{-2}$ & $5.99 \times 10^{-2}$ & $6.78 \times 10^{-2}$ & $7.51 \times 10^{-2}$ & $8.44 \times 10^{-2}$ \\
1 & $1.90 \times 10^{-1}$ & $2.07 \times 10^{-1}$ & $2.31 \times 10^{-1}$ & $2.53 \times 10^{-1}$ & $2.81 \times 10^{-1}$ \\
$x^{i d l}$ & $6.35 \times 10^{-2}$ & $7.36 \times 10^{-2}$ & $8.50 \times 10^{-2}$ & $9.79 \times 10^{-2}$ & $1.12 \times 10^{-1}$ \\
\hline
\end{tabular}

a The relative uncertainties $u_{r}$ are $u_{r}(T)=0.01 \mathrm{~K}, u_{r}(m)=0.00, u_{r}(p)=0.00$ and $u_{r}\left(x_{e}\right)=0.01$.

The logarithmic solubility of Yalkowsky-Roseman model $\left(\log x^{Y a l}\right)$ for FFA in mixed solvent systems was predicted using the following equation [37]:

$$
\log x^{Y a l}=m_{1} \log x_{1}+m_{2} \log x_{2}
$$

where $x_{1}=$ mole fraction solubility of FFA in pure Carbitol, $x_{2}=$ mole fraction solubility of FFA in pure water, $m_{1}=$ Carbitol mass fraction and $m_{2}=$ water mass fraction. The correlation between the experimental and Yalkowsky-Roseman solubilities of FFA was performed in terms of RMSD.

The Jouyban-Acree model solubility $\left(x_{m, T}\right)$ of FFA in mixed solvent systems was predicted using the following equation [38-40]:

$$
\ln x_{m, T}=m_{1} \ln x_{1}+m_{2} \ln x_{2}+\left\lceil m_{1} m_{2} \sum_{i=0}^{2} \frac{J_{i}}{T}\left(m_{1}-m_{2}\right)^{i}\right\rceil
$$

where $J_{i}=$ model coefficient of Equation (12) and was predicted using no-intercept regression analysis [41]. The correlation between the experimental and Jouyban-Acree model solubilities of FFA was performed in terms of RMSD.

The Jouyban-Acree-van't Hoff solubility of FFA in mixed solvent systems was predicted using the following equation [41,42]:

$$
\ln x_{m, T}=m_{1}\left(A_{1}+\frac{B_{1}}{T}\right)+m_{2}\left(A_{2}+\frac{B_{2}}{T}\right)+\left[\frac{m_{1} m_{2}}{T} \sum_{i=0}^{2} J_{i}\left(m_{1}-m_{2}\right)^{i}\right]
$$


where $A_{1}, B_{1}, A_{2}, B_{2}$ and $J_{i}=$ model coefficients of Equation (13). The correlation between the experimental and Jouyban-Acree-van't Hoff model solubilities of FFA was performed in term of RMSD.

\subsection{Statistical Evaluation}

Statistical evaluation was carried out using the Kruskal-Wallis test, followed by Dunn's test using GraphPad InStat software (San Diego, CA, USA). This test was performed to evaluate the statistical differences of FFA solubility. The $p<0.05$ was taken as a significant value.

\section{Results and Discussion}

\subsection{Solubility Data of FFA in Various Carbitol + Water Mixtures and Their Literature Comparison}

The experimental solubilities of FFA in mixed solvent systems and neat solvents at $T=298.2-318.2 \mathrm{~K}$ and $p=0.1 \mathrm{MPa}$ are tabulated in Table 2 .

The solubility of FFA in different Carbitol + water mixtures has not been studied and reported so far. However, the mole fraction solubility of FFA in pure water at $T=295.2 \mathrm{~K}$ was found as $4.29 \times$ $10^{-7}$ in literature [3]. In another report, the mole fraction solubility of FFA in pure water at $T=298.2 \mathrm{~K}$ has been reported as $5.83 \times 10^{-7}$ [4]. The mole fraction solubility of FFA in pure water at $T=298.2 \mathrm{~K}$ was determined as $5.80 \times 10^{-7}$ in the present study (Table 2). The mole fraction solubility of FFA in pure water recorded in the present work was in accordance with those reported in literature. The mole fraction solubility of FFA in pure Carbitol at $T=298.2 \mathrm{~K}$ has been reported as $1.93 \times 10^{-1}$ in literature [4]. The mole fraction solubility of FFA in neat Carbitol at $T=298.2 \mathrm{~K}$ was determined as $1.90 \times 10^{-1}$ in the present study (Table 2). The mole fraction solubility of FFA in pure Carbitol recorded in the present work was also in accordance with its literature value [4].

The mole fraction solubilities of FFA in pure water and pure Carbitol at five different temperatures, i.e., $T=298.2-318.2 \mathrm{~K}$, have also been studied and reported in literature [4]. The graphical correlation of the $x_{\mathrm{e}}$ value of FFA in pure water and pure Carbitol at $T=298.2-318.2 \mathrm{~K}$ is summarized in Figure 2A and B, respectively, showing a good correlation of $x_{\mathrm{e}}$ data of FFA with those reported in literature. The RMSD values between the experimental and literature solubilities of FFA in neat water and neat Carbitol at five different temperatures were recorded as $2.21 \%$ and $1.22 \%$, respectively. These results suggested good agreement of experimental solubilities of FFA with its literature values.
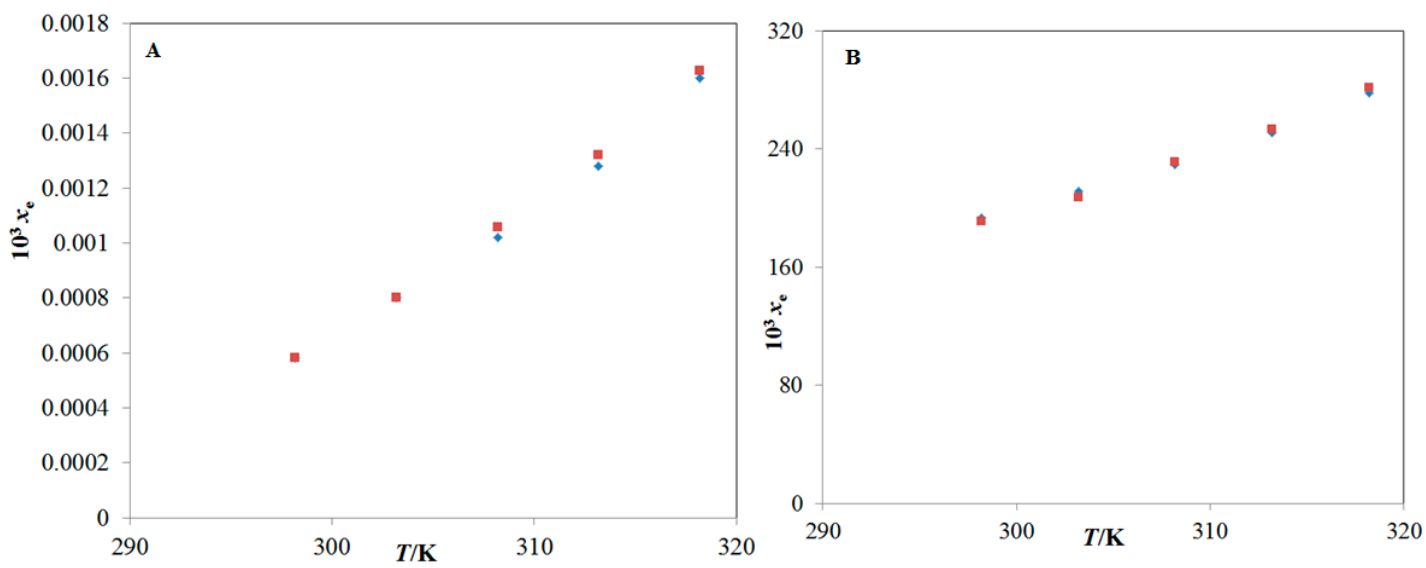

Figure 2. Graphical comparison of FFA solubility in (A) pure water and (B) pure Carbitol with reported values at $T=298.2-318.2 \mathrm{~K}$. The symbol $\square$ represents the experimental solubilities of FFA in (A) pure water and (B) pure Carbitol, and the symbol $\bullet$ represents the reported solubilities of FFA in (A) pure water and (B) pure Carbitol taken from reference [4]. 
The experimental reliability proof of the method of solubility measurement was verified by the measurement of the solubility of sodium chloride in neat water at $T=298.15 \mathrm{~K}$ and $T=323.15 \mathrm{~K}$. The solubility of sodium chloride in neat water at $T=298.15 \mathrm{~K}$ and $T=323.15 \mathrm{~K}$ was found as 0.26483 in mass fraction (converted to $9.99 \times 10^{-2}$ in mole fraction) and 0.26889 in mass fraction (converted to $1.02 \times 10^{-1}$ in fraction), respectively [23]. The mole fraction solubility of sodium chloride in neat water at $T=298.15 \mathrm{~K}$ and $T=323.15 \mathrm{~K}$ was obtained as $9.96 \times 10^{-2}$ and $1.04 \times 10^{-1}$, respectively, in the present work. The RMSD between the experimental and literature solubility of sodium chloride was found to be $1.23 \%$. These observations suggested that the solubility of sodium chloride in pure water obtained using the current method was in accordance with its literature data [23]. Therefore, the present method of solubility measurement was reliable and precise for the solubility determination of FFA.

From the data summarized in Table 2, it was observed that the solubilities of FFA were found to enhance linearly with an increase in temperature and Carbitol mass fraction in all mixed solvent systems and pure solvents $(p<0.05)$. Therefore, the maximum solubility of FFA was obtained in pure Carbitol $\left(2.81 \times 10^{-1}\right.$ at $\left.T=318.2 \mathrm{~K}\right)$, and the minimum one was found in pure water $\left(5.80 \times 10^{-7}\right.$ at $T=298.2 \mathrm{~K}$ ). The maximum solubility of FFA in pure Carbitol was probably due to the lower polarity and lower HSP of Carbitol compared with water [13-15]. The influence of Carbitol mass fraction on logarithmic solubility $\left(\ln x_{\mathrm{e}}\right)$ value of FFA at $T=298.2-318.2 \mathrm{~K}$ was also studied, and the results are presented in Figure 3.

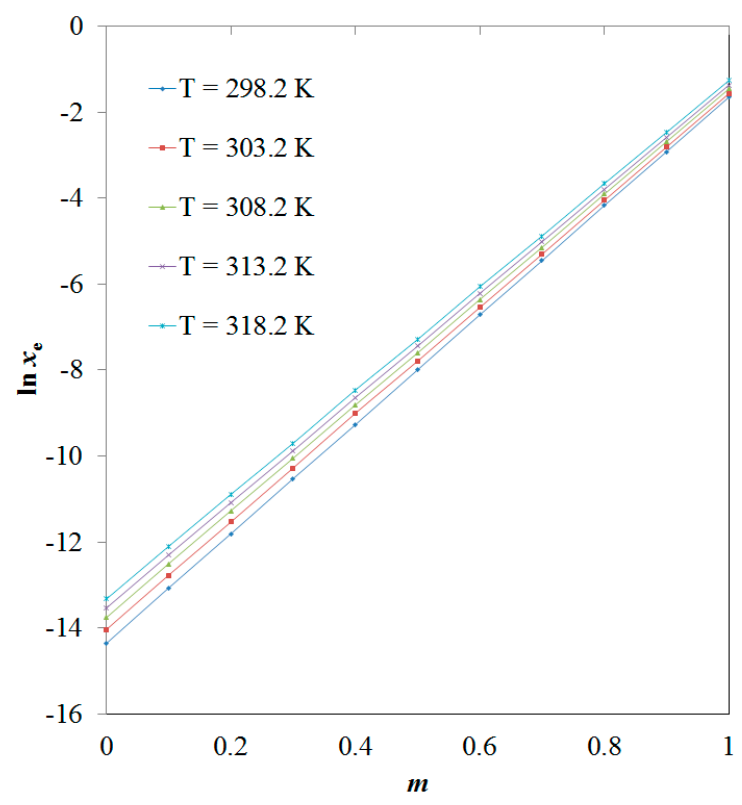

Figure 3. Influence of Carbitol mass fraction $(m)$ on FFA logarithmic solubility $\left(\ln x_{e}\right)$ at $T=298.2-318.2 \mathrm{~K}$.

The results presented in Figure 3 indicate a significant enhancement in the logarithmic solubility of FFA with an increase in Carbitol mass fraction in mixed solvent systems at $T=298.2-318.2 \mathrm{~K}(p<0.05)$. It was also noted that the logarithmic solubilities of FFA increased significantly from pure water to pure Carbitol $(p<0.05)$ at each temperature studied. Hence, Carbitol can be used as a potential cosolvent in the liquid formulation design of FFA.

\subsection{HSPS}

Hansen solubility parameters provide a numerical estimate of the degree of interaction between the solute and solvent and could be a good indication of solubility/miscibility [24]. The solute and solvents with similar solubility parameters are likely to be soluble/miscible with each other [43]. Similar solubility parameters also indicate a similar polarity between the solute and solvent. Hence, Hansen solubility 
parameters of FFA, pure water and pure Carbitol were estimated in this work. The estimation of Hansen solubility parameters have various applications in different areas of research $[24,43]$. In the current work, the main application was to obtain information about the solubility/miscibility between the solute and solvent. The $\delta_{\mathrm{t}}$ value for FFA was estimated as $20.90 \mathrm{MPa}^{1 / 2}$ using HSPiP software. However, the values of $\delta_{1}$ for pure Carbitol and $\delta_{2}$ for pure water were estimated as 21.40 and $47.80 \mathrm{MPa}^{1 / 2}$, respectively, using HSPiP software. The HSP of pure Carbitol $\left(\delta_{1}=21.40 \mathrm{MPa}^{1 / 2}\right)$ was found to be closest to that of FFA $\left(\delta_{t}=20.90 \mathrm{MPa}^{1 / 2}\right)$. Hence, FFA was highly soluble/miscible in Carbitol compared with water. The recorded data of the HSPs were in accordance with $x_{e}$ values of FFA in mixed solvent systems.

\subsection{Solute-Solvent Interactions and Determination of Ideal Solubility and Activity Coefficients}

The $x^{i d l}$ values of FFA at $T=298.2-318.2 \mathrm{~K}$ are tabulated in Table 2 . The $x^{\text {idl }}$ values of FFA were found as $6.35 \times 10^{-2}$ to $1.12 \times 10^{-1}$ at $T=298.2-318.2 \mathrm{~K}$. The $x^{\text {idl }}$ values of FFA were significantly higher compared to its experimental solubilities in water $(p<0.05)$, while the $x^{\text {idl }}$ values of FFA were significantly lower compared to its experimental solubilities in Carbitol $(p<0.05)$. Due to the maximum experimental solubility of FFA in Carbitol, it can be used as an ideal cosolvent for the solubility enhancement of FFA.

The $\gamma_{\mathrm{i}}$ values for FFA in mixed solvent systems at $T=298.2-318.2 \mathrm{~K}$ are tabulated in Table 3.

Table 3. Activity coefficients $\left(\gamma_{i}\right)$ of FFA in various Carbitol + water mixtures $(m)$ at $T=298.2-318.2 \mathrm{~K}$.

\begin{tabular}{cccccc}
\hline \multirow{2}{*}{$\boldsymbol{c}$} & \multicolumn{5}{c}{$\gamma_{\boldsymbol{i}}$} \\
\cline { 2 - 6 } & $\boldsymbol{T = 2 9 8 . 2 ~ K}$ & $\boldsymbol{T}=\mathbf{3 0 3 . 2 ~ K}$ & $\boldsymbol{T}=\mathbf{3 0 8 . 2} \mathbf{K}$ & $\boldsymbol{T}=\mathbf{3 1 3 . 2} \mathbf{K}$ & $\boldsymbol{T}=\mathbf{3 1 8 . 2 ~ K}$ \\
\hline 0.0 & 110,000 & $91,900.0$ & $80,400.0$ & $74,200.0$ & $69,200.0$ \\
0.1 & $30,323.3$ & $25,981.8$ & $22,959.3$ & $21,588.6$ & $20,326.8$ \\
0.2 & 8567.52 & 7541.16 & 6691.26 & 6385.92 & 6056.82 \\
0.3 & 2379.81 & 2148.02 & 1977.9 & 1916.43 & 1846.53 \\
0.4 & 677.404 & 601.039 & 570.85 & 555.446 & 534.634 \\
0.5 & 188.975 & 178.627 & 170.372 & 167.843 & 164.91 \\
0.6 & 52.4835 & 51.2066 & 49.1446 & 49.0884 & 48.3886 \\
0.7 & 14.9338 & 14.8694 & 14.6094 & 14.7924 & 14.8495 \\
0.8 & 4.13227 & 4.24933 & 4.24812 & 4.37149 & 4.4018 \\
0.9 & 1.18203 & 1.22716 & 1.2527 & 1.30404 & 1.3335 \\
1 & 0.333385 & 0.355174 & 0.367864 & 0.387139 & 0.400476 \\
\hline
\end{tabular}

The $\gamma_{i}$ values for FFA were found to be larger in pure water compared to pure Carbitol and mixed solvent systems at each temperature investigated $(p<0.05)$. However, the $\gamma_{i}$ values for FFA were observed to be the minimum in pure Carbitol at each temperature investigated. The $\gamma_{i}$ values were obtained as $<1.0$ in pure Carbitol. The $\gamma_{i}$ values for FFA were found to reduce significantly with the rise in temperature at $m=0.0-0.5(p<0.05)$. However, there was no significant change in $\gamma_{i}$ values of FFA at $m=0.6-1.0(p>0.05)$. The $\gamma_{i}$ values for FFA were found to decrease significantly from neat water to neat Carbitol $(p<0.05)$. The larger $\gamma_{i}$ of FFA in neat water might be due to the minimum solubility of FFA in water compared with neat Carbitol $[12,13]$. The obtained data of activity coefficients for FFA in mixed solvent systems were in accordance with their solubility results [13]. Based on these results, higher solute-solvent interactions were considered in FFA-Carbitol compared to FFA-water.

\subsection{Apparent Thermodynamic Analysis of FFA Solution}

The physical quantities of different apparent thermodynamic parameters for FFA dissolution in mixed solvent systems and pure solvents are tabulated in Table 4. 
Table 4. Apparent standard enthalpy $\left(\Delta_{\text {sol }} H^{0}\right)$, apparent standard Gibbs energy $\left(\Delta_{s o l} G^{0}\right)$, apparent standard entropy $\left(\Delta_{\text {sol }} S^{0}\right)$ and determination coefficient $\left(R^{2}\right)$ values for FFA dissolution in various Carbitol + water mixtures $(m)^{\mathrm{b}}$.

\begin{tabular}{|c|c|c|c|c|}
\hline$m$ & $\Delta_{\text {sol }} H^{0} / \mathrm{kJ} \mathrm{mol}^{-1}$ & $\Delta_{s o l} G^{0} / \mathrm{kJ} \mathrm{mol}^{-1}$ & $\Delta_{\text {sol }} S^{0} / \mathrm{J} \mathrm{mol}^{-1} \mathrm{~K}^{-1}$ & $R^{2}$ \\
\hline 0 & 40.56 & 35.35 & 16.91 & 0.9942 \\
\hline 0.1 & 38.08 & 32.14 & 19.31 & 0.9943 \\
\hline 0.2 & 36.21 & 28.98 & 23.45 & 0.9946 \\
\hline 0.3 & 32.43 & 25.83 & 21.41 & 0.9956 \\
\hline 0.4 & 31.34 & 22.63 & 28.26 & 0.9937 \\
\hline 0.5 & 27.88 & 19.52 & 27.14 & 0.998 \\
\hline 0.6 & 25.82 & 16.33 & 30.79 & 0.9989 \\
\hline 0.7 & 22.84 & 13.21 & 31.25 & 0.9992 \\
\hline 0.8 & 20.12 & 10.04 & 32.74 & 0.9987 \\
\hline 0.9 & 17.8 & 6.9 & 35.37 & 0.9992 \\
\hline 1 & 15.41 & 3.75 & 37.83 & 0.9973 \\
\hline
\end{tabular}

${ }^{\mathrm{b}}$ Mean relative uncertainties are $u\left(\Delta_{\text {sol }} H^{0}\right)=0.30, u\left(\Delta_{\text {sol }} G^{0}\right)=0.53$ and $u\left(\Delta_{\text {sol }} S^{0}\right)=0.24$.

The $\Delta_{\text {sol }} H^{0}$ values for FFA in mixed solvent systems and neat solvents were recorded as 15.41-40.55 kJ mol ${ }^{-1}$. The $\Delta_{\text {sol }} H^{0}$ values of FFA were recorded as decreasing with an increase in the $m$ value of Carbitol in mixed solvent systems and solubilities of FFA. Therefore, the maximum $\Delta_{\text {sol }} H^{0}$ was obtained in neat water $\left(40.56 \mathrm{~kJ} \mathrm{~mol}^{-1}\right)$, while the minimum one was estimated in neat Carbitol $\left(15.41 \mathrm{~kJ} \mathrm{~mol}^{-1}\right)$.

The $\Delta_{s o l} G^{0}$ values for FFA in mixed solvent systems were found as $3.75-35.35 \mathrm{~kJ} \mathrm{~mol}^{-1}$. The $\Delta_{\text {sol }} G^{0}$ values for FFA also decreased with an increase in $m$ value of Carbitol in mixed solvent systems and solubilities of FFA. The maximum and minimum $\Delta_{s o l} G^{0}$ for FFA was estimated in neat water $\left(35.35 \mathrm{~kJ} \mathrm{~mol}^{-1}\right)$ and neat Carbitol $\left(3.75 \mathrm{~kJ} \mathrm{~mol}^{-1}\right)$, respectively. The recorded positive value of $\Delta_{\text {sol }} H^{0}$ and $\Delta_{s o l} G^{0}$ for FFA suggested an endothermic dissolution of FFA in all Carbitol + water mixtures investigated $[25,26]$.

The $\Delta_{\text {sol }} S^{0}$ values for FFA in mixed solvent systems were estimated as $16.91-37.83 \mathrm{~J} \mathrm{~mol}^{-1} \mathrm{~K}^{-1}$, indicating the entropy-driven dissolution of FFA in all mixed solvent systems, including neat water and neat Carbitol [26]. The average relative uncertainties in $\Delta_{\text {sol }} H^{0}, \Delta_{s o l} G^{0}$ and $\Delta_{\text {sol }} S^{0}$ were recorded as $0.30,0.53$ and 0.24 , respectively. Based on recorded thermodynamic quantities, the final dissolution of FFA was proposed as endothermic and entropy-driven in all mixed solvent systems and neat solvents $[25,26]$.

\subsection{Enthalpy-Entropy Compensation Analysis}

The solvation property of FFA in mixed solvent systems was evaluated by applying enthalpyentropy compensation analysis. The results are shown in Figure 4.

It was observed that FFA in all mixed solvent systems and neat solvents showed a non-linear $\Delta_{\text {sol }} H^{\circ}$ vs. $\Delta_{\text {sol }} G^{\circ}$ graph, and the value of the slope was positive. Based on such observation, the driving mechanism for FFA solvation was considered as enthalpy-driven in all mixed solvent systems and neat solvents. This observation was possible due to the higher solvation of FFA in neat Carbitol molecules compared with neat water molecules [32]. The solvation property of FFA in mixed solvent systems was in accordance with those reported for the solvation properties of various poorly water-soluble drugs, such as sunitinib malate, apigenin, apremilast, pyridazinone derivative, celecoxib and lamotrigine, in various Carbitol + water mixtures [10-15]. 


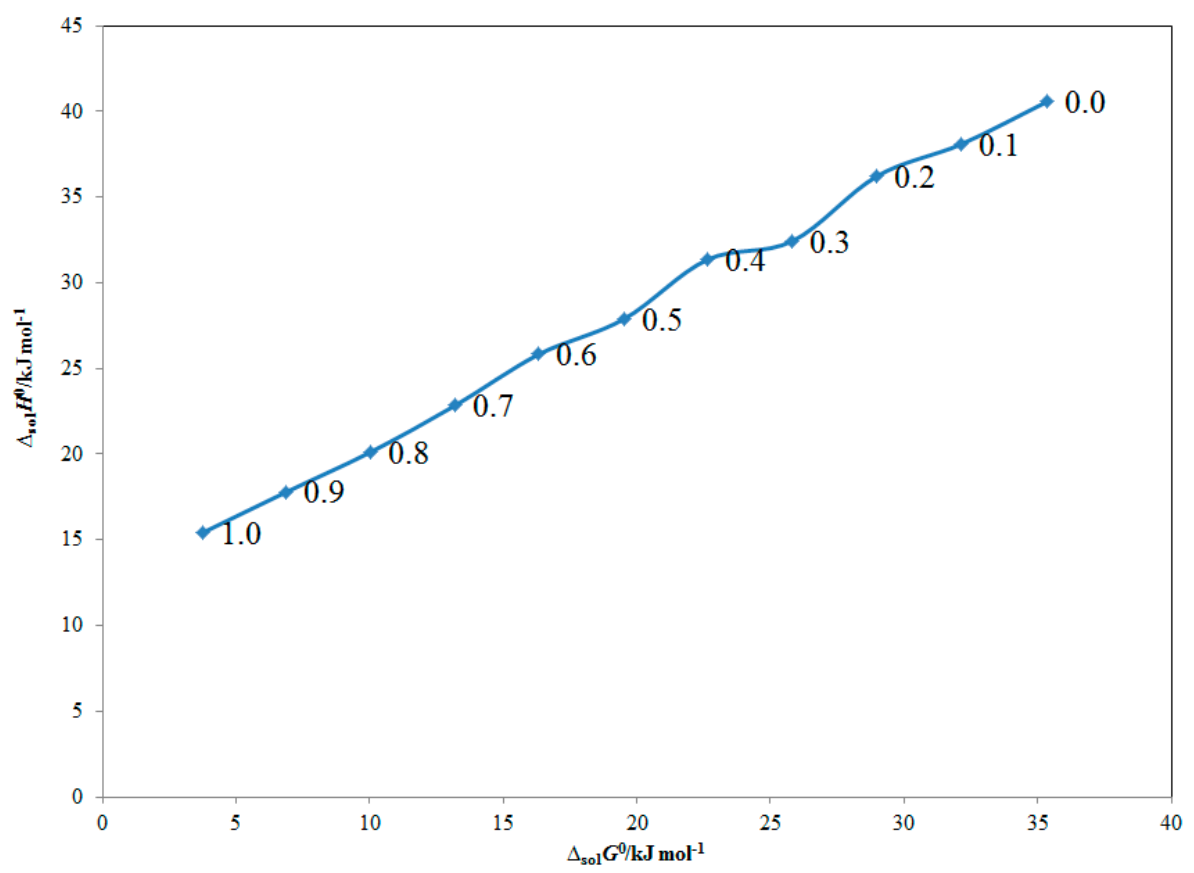

Figure 4. Apparent standard enthalpy $\left(\Delta_{\text {sol }} H^{0}\right)$ vs. apparent standard Gibbs energy $\left(\Delta_{\text {sol }} G^{0}\right)$ enthalpyentropy compensation analysis graph for FFA solubility in various mixed solvent systems at the mean harmonic temperature $\left(T_{h m}\right)=308 \mathrm{~K}$.

\subsection{Computation Modeling}

The experimental solubilities of FFA were validated with van't Hoff, Apelblat, Yalkowsky-Roseman, Jouyban-Acree and Jouyban-Acree-van't Hoff models [34-40]. The results of the van't Hoff model for FFA in mixed solvent systems, including neat solvents, are tabulated in Table 5.

Table 5. The parameters of van't Hoff model ( $a$ and $b$ ) along with $R^{2}$ and root mean square deviations (\% RMSDs) for FFA in various Carbitol + water combinations $(m)^{\mathrm{c}}$.

\begin{tabular}{cccccc}
\hline $\boldsymbol{m}$ & $\boldsymbol{a}$ & $\boldsymbol{b}$ & $\boldsymbol{R}^{\mathbf{2}}$ & RMSD (\%) & Overall RMSD (\%) \\
\hline 0 & 2.01 & -4872.80 & 0.9944 & 2.73 & \\
0.1 & 2.3 & -4575.50 & 0.9945 & 2.53 & \\
0.2 & 2.8 & -4350.00 & 0.9947 & 2.35 & \\
0.3 & 2.55 & -3896.20 & 0.9957 & 2.03 & \\
0.4 & 3.38 & -3765.20 & 0.9939 & 2.2 & \\
0.5 & 3.24 & -3349.90 & 0.9981 & 1.39 & \\
0.6 & 3.68 & -3101.10 & 0.9989 & 1.03 & \\
0.7 & 3.74 & -2744.30 & 0.9992 & 0.84 & \\
0.8 & 3.92 & -2417.60 & 0.9987 & 0.97 & \\
0.9 & 4.24 & -2138.30 & 0.9992 & 0.62 & \\
1 & 4.54 & -1850.90 & 0.9972 & 0.73 & \\
\hline \multicolumn{7}{c}{}
\end{tabular}

${ }^{\mathrm{c}}$ The average relative uncertainties are $u(a)=0.24$ and $u(b)=0.30$.

RMSDs for FFA in mixed solvent systems and neat solvents were recorded as 0.62 to $2.73 \%$, with a mean RMSD value of $1.58 \%$. The $R^{2}$ values for the van't Hoff model were predicted as $0.9939-0.9992$. The graphical correlation between the experimental and van't Hoff model solubilities of FFA is shown in Figure S2, suggesting a good correlation of experimental solubilities of FFA with the van't Hoff model.

The results of the Apelblat model for FFA in mixed solvent systems and neat solvents are tabulated in Table 6. 
Table 6. The parameters of Apelblat model $\left(A, B\right.$ and $C$ ) along with $R^{2}$ and $\%$ RMSDs for FFA in various Carbitol + water combinations $(m)^{\mathrm{d}}$.

\begin{tabular}{ccccccc}
\hline $\boldsymbol{m}$ & $\boldsymbol{A}$ & $\boldsymbol{B}$ & $\boldsymbol{C}$ & $\boldsymbol{R}^{\mathbf{2}}$ & $\boldsymbol{R}$ RSD (\%) & Overall RMSD (\%) \\
\hline 0 & 939.33 & $-47,907.30$ & -139.18 & 0.9993 & 1.43 & \\
0.1 & 846.56 & $-43,337.80$ & -125.36 & 0.999 & 1.37 & \\
0.2 & 750.42 & $-38,676.20$ & -111.01 & 0.9985 & 1.31 & \\
0.3 & 618.72 & $-32,187.80$ & -91.49 & 0.999 & 1.16 & \\
0.4 & 677.29 & $-34,706.60$ & -100.07 & 0.9982 & 1.46 & \\
0.5 & 354.45 & $-19,479.00$ & -52.14 & 0.9995 & 0.7 & \\
0.6 & 143.72 & -9538.04 & -20.79 & 0.999 & 0.64 & \\
0.7 & 110.9 & -7670.58 & -15.90 & 0.9993 & 0.55 & \\
0.8 & -132.19 & 3822.7 & 20.21 & 0.999 & 0.78 & \\
0.9 & -97.61 & 2530.17 & 15.13 & 0.9994 & 0.41 & \\
1 & -219.47 & 8425.15 & 33.27 & 0.9992 & 0.64 & \\
\hline \multicolumn{7}{c}{ d The average relative uncertainties are $u(A)=1.16, u(B)=1.02$ and $u(C)=1.17}$.
\end{tabular}

The RMSDs for FFA in mixed solvent systems and neat solvents were obtained as $0.41-1.46 \%$, with a mean RMSD of $0.95 \%$. The $R^{2}$ values for the Apelblat model were predicted as $0.9982-0.9995$. Graphical correlation between the experimental and Apelblat model solubilities of FFA is shown in Figure S3 and shows good correlation of the experimental solubilities of FFA with the Apelblat model.

The results of the Yalkowsky-Roseman model for FFA in mixed solvent systems are included in Table 7. The RMSDs for this model were predicted as $0.42-3.14 \%$, with a mean RMSD value of $1.53 \%$.

Table 7. $\log x^{Y a l}$ values of FFA obtained by Yalkowsky-Roseman model in various Carbitol + water combinations $(m)$ at $T=298.2-318.2 \mathrm{~K}$.

\begin{tabular}{|c|c|c|c|c|c|c|c|}
\hline \multirow{2}{*}{$m$} & \multicolumn{5}{|c|}{$\log x^{Y a l}$} & \multirow{2}{*}{ RMSD (\%) } & \multirow{2}{*}{ Overall RMSD (\%) } \\
\hline & $298.2 \mathrm{~K}$ & $303.2 \mathrm{~K}$ & $308.2 \mathrm{~K}$ & $313.2 \mathrm{~K}$ & $318.2 \mathrm{~K}$ & & \\
\hline 0.1 & -5.68 & -5.55 & -5.44 & -5.35 & -5.26 & 1.83 & \\
\hline 0.2 & -5.13 & -5.01 & -4.90 & -4.82 & -4.74 & 1.8 & \\
\hline 0.3 & -4.58 & -4.47 & -4.37 & -4.29 & -4.21 & 1.35 & \\
\hline 0.4 & -4.02 & -3.93 & -3.83 & -3.76 & -3.69 & 3.14 & \\
\hline 0.5 & -3.47 & -3.38 & -3.30 & -3.23 & -3.16 & 0.99 & 1.53 \\
\hline 0.6 & -2.92 & -2.84 & -2.77 & -2.70 & -2.64 & 2.23 & \\
\hline 0.7 & -2.37 & -2.30 & -2.23 & -2.18 & -2.12 & 0.55 & \\
\hline 0.8 & -1.82 & -1.76 & -1.70 & -1.65 & -1.59 & 1.46 & \\
\hline 0.9 & -1.27 & -1.22 & -1.17 & -1.12 & -1.07 & 0.42 & \\
\hline
\end{tabular}

Results of the Jouyban-Acree model and Jouyban-Acree-van't Hoff models for FFA in mixed solvent systems are tabulated in Table 8. The mean RMSD for the Jouyban-Acree model was predicted as $0.76 \%$, and the mean RMSD for the Jouyban-Acree-van't Hoff model was predicted as $0.88 \%$.

Table 8. The parameters of Jouyban-Acree and Jouyban-Acree-van't Hoff models for FFA in Carbitol + water mixtures.

\begin{tabular}{ccccc}
\hline System & \multicolumn{2}{c}{ Jouyban-Acree } & \multicolumn{2}{c}{ Jouyban-Acree-van't Hoff } \\
\hline & & & $A_{1}$ & 4.54 \\
Carbitol + water & $J_{\mathrm{i}}$ & 86.01 & $B_{1}$ & -1850.90 \\
& & & $A_{2}$ & 2.01 \\
& & & $B_{2}$ & -4872.80 \\
& & & $J_{i}$ & 74.42 \\
RMSD (\%) & \multicolumn{2}{c}{0.76} & \multicolumn{2}{c}{0.88} \\
\hline
\end{tabular}


Overall, all models demonstrated good correlation based on low RMSD values. However, the error values of each model were not comparable to each other. The error values of all models were closed to the experimental uncertainties. This observation suggested that all studied models reproduced the experimental solubility data with minimum error values. Apelblat and van't Hoff models are semi-predictive models and correlate the solubility at different temperatures at the given set of cosolvent mixtures. Jouyban-Acree and Jouyban-Acree-van't Hoff models predict the solubility in the mixed solvents at the given set of temperatures. The Yalkowsky-Roseman model is a special case of the Jouyban-Acree model with the adjustable parameter fixed and equal to zero. Among different computational models utilizing adjustable parameters, the performance of the Jouyban-Acree model was the best because it utilized the least number of adjustable parameters compared to other models. Hence, the Jouyban-Acree model can be utilized as the best model for solubility correlation compared to other models utilizing adjustable parameters. Among the five different models studied, the Yalkowsky-Roseman model had a serious advantage as it did not require any adjustable parameter. Based on these observations, the Yalkowsky-Roseman model was found to be the best model among all five different models for the correlation as it utilized no adjustable parameters.

\section{Conclusions}

The solubilization, HSPs, solvation behavior and solution thermodynamics of FFA in various Carbitol + water mixtures and neat solvents at $T=298.2-318.2 \mathrm{~K}$ and $p=0.1 \mathrm{MPa}$ were evaluated in this study. The recorded solubility of FFA was regressed with the van't Hoff, Apelblat, Yalkowsky-Roseman, Jouyban-Acree and Jouyban-Acree-van't Hoff models. The solubility of FFA was found to be enhanced significantly with an increase in temperature and Carbitol mass fraction in all mixed solvent systems and pure solvents. The solubility data of FFA was in accordance with its HSPs. The results of activity coefficients suggested higher molecular interactions in FFA-Carbitol compared to FFA-water. Thermodynamic studies indicated an endothermic and entropy-driven dissolution of FFA in all mixed solvent systems and neat solvents. Enthalpy-entropy compensation analysis studies showed that the solvation of FFA was enthalpy driven in all mixed solvent systems and neat solvents.

Supplementary Materials: The following are available online at http://www.mdpi.com/2227-9717/8/10/1204/s1 . This manuscript contains supplementary materials that can be found online. The van't Hoff graphs for the determination of different thermodynamic parameters are presented in Figure S1. The correlation between the experimental and van't Hoff model solubilities of FFA at five different temperatures is presented in Figure S2. The correlation between experimental and Apelblat model solubilities of FFA at five different temperatures is presented in Figure S3.

Author Contributions: Conceptualization, supervision, F.S.; methodology, F.S. and S.A.; validation, F.S. and S.A.; writing—original draft, F.S.; writing—review and editing, S.A. and F.S.; Software, F.S. All authors have read and agreed to the published version of the manuscript.

Funding: This research was funded by the Researcher Supporting Project (number RSP-2020/146) at King Saud University, Riyadh, Saudi Arabia, and the article processing charge (APC) was also supported by RSP.

Acknowledgments: The authors are thankful to the Researcher Supporting Project (number RSP-2020/146) at King Saud University, Riyadh, Saudi Arabia.

Conflicts of Interest: The authors report no conflicts of interest associated with this manuscript.

\section{References}

1. Acree, W.E., Jr. IUPAC-NIST solubility data series. 102. Solubility of non-steroidal anti-inflammatory drugs (NSAIDs) in neat organic solvents and organic solvent mixtures. J. Phys. Chem. Ref. Data 2014, 43, E023102. [CrossRef]

2. Perlovich, G.L.; Surov, A.O.; Bauer-Brandl, A. Thermodynamic properties of flufenamic and niflumic acids-Specific and non-specific interactions in solution and in crystal lattices, mechanism of solvation, partitioning and distribution. J. Pharm. Biomed. Anal. 2007, 45, 679-687. [CrossRef]

3. Shazly, G.A.; Ibrahim, M.A.; Badran, M.M.; Zuheir, K.M.A. Utilizing Pluronic F-127 and Gelucire 50/13 solid dispersions for enhanced skin delivery of flufenamic acid. Drug Dev. Res. 2012, 73, 299-307. [CrossRef] 
4. Alshehri, S.; Shakeel, F. Solubility measurement, thermodynamics and molecular interactions of flufenamic acid in different neat solvents. J. Mol. Liq. 2017, 240, 447-453. [CrossRef]

5. Kale, A.R.; Kakade, S.; Bhosale, A. A review on: Solubility enhancement techniques. Curr. Pharm. Res. 2020, 10, 3630-3647.

6. Mohammadian, E.; Rahimpour, E.; Martinez, F.; Jouyban, A. Budesonide solubility in polyethylene glycol 400 + water at different temperatures: Experimental measurement and mathematical modelling. J. Mol. Liq. 2019, 274, 418-425. [CrossRef]

7. Dadmand, S.; Kamari, F.; Acree, W.E., Jr.; Jouyban, A. Solubility prediction of drugs in binary solvent mixtures at various temperatures using a minimum number of experimental data points. AAPS PharmSciTech. 2019, 20, E10. [CrossRef]

8. Shakeel, F.; Alshehri, S.; Imran, M.; Haq, N.; Alanazi, A.; Anwer, M.K. Experimental and computational approaches for solubility measurement of pyridazinone derivative in binary (DMSO + water) systems. Molecules 2020, 25, 171. [CrossRef]

9. Shakeel, F.; Haq, N.; Raish, M.; Anwer, M.K.; Al-Shdefat, R. Solubility and thermodynamic analysis of sinapic acid in various neat solvents at different temperatures. J. Mol. Liq. 2016, 222, 167-171. [CrossRef]

10. Alshehri, S.; Shakeel, F. Solubility determination, various solubility parameters and solution thermodynamics of sunitinib malate in some cosolvents, water and various (Transcutol + water) mixtures. J. Mol. Liq. 2020, 307, E112970. [CrossRef]

11. Shakeel, F.; Alshehri, S.; Haq, N.; Elzayat, E.; Ibrahim, M.; Altamimi, M.A.; Mohsin, K.; Alanazi, F.K.; Alsarra, I.A. Solubility determination and thermodynamic data of apigenin in binary (Transcutol ${ }^{\circledR}+$ water) mixtures. Ind. Crops Prod. 2018, 116, 56-63. [CrossRef]

12. Shakeel, F.; Haq, N.; Alanazi, F.K.; Alsarra, I.A. Solubility and thermodynamic function of apremilast in different (Transcutol + water) cosolvents mixtures: Measurement, correlation and molecular interactions. J. Ind. Eng. Chem. 2017, 56, 99-107. [CrossRef]

13. Shakeel, F.; Imran, M.; Abida, H.N.; Alanazi, F.K.; Alsarra, I.A. Solubility and thermodynamic/solvation behavior of 6-phenyl-4,5-dihydropyridazin-3(2H)-one in different (Transcutol + water) mixtures. J. Mol. Liq. 2017, 230, 511-517. [CrossRef]

14. Norouzi, F.; Jouyban, A.; Martínez, F.; Barzegar-Jalali, M.; Rahimpour, E. Solubility of celecoxib in carbitol + water mixtures at various temperatures: Experimental data and mathematical modeling. Phys. Chem. Liq. 2019, 57, 755-767. [CrossRef]

15. Barzegar-Jalali, M.; Rahimpour, E.; Martínez, F.; Jouyban, A. Solubility and thermodynamics of lamotrigine in carbitol + water mixtures from $T=(293.2$ to 313.2) K. Chem. Eng. Comm. 2018, 206, 182-192. [CrossRef]

16. Moffat, A.C. Clarke's Isolation and Identification of Drugs; Pharmaceutical Press: London, UK, 1986.

17. Wenkers, B.P.; Lippold, B.C. Skin penetration of nonsteroidal anti-inflammatory drugs out of a lipophilic vehicle: Influence of the viable epidermis. J. Pharm. Sci. 1999, 88, 1326-1331. [CrossRef]

18. Rytting, E.; Lentz, K.A.; Chen, X.Q.; Qian, F.; Venkatesh, S. Aqueous and cosolvent solubility data for drug-like organic compounds. AAPS J. 2005, 7, E10. [CrossRef]

19. Lee, E.H.; Byrn, S.R.; Pinal, R. The solution properties of mefenamic acid and a closely related analogue are indistinguishable in polar solvents but significantly different in nonpolar environments. J. Pharm. Sci. 2012, 101, 4529-4539. [CrossRef]

20. Surov, A.O.; Szterner, P.; Zielenkiewicz, W.; Perlovich, G.L. Thermodynamic and structural study of tolfenamic acid polymorphs. J. Pharm. Biomed. Anal. 2009, 50, 831-840. [CrossRef]

21. Domanska, U.; Pobudkowska, A.; Pelczarska, A. Solubility of sparingly soluble drug derivatives of anthranilic acid. J. Phys. Chem. B 2011, 115, 2547-2554. [CrossRef]

22. Higuchi, T.; Connors, K.A. Phase-solubility techniques. Adv. Anal. Chem. Inst. 1965, 4, 117-122.

23. Pinho, S.P.; Macedo, E.A. Solubility of $\mathrm{NaCl}, \mathrm{NaBr}$, and $\mathrm{KCl}$ in water, methanol, ethanol, and their mixed solvents. J. Chem. Eng. Data 2005, 50, 29-32. [CrossRef]

24. Zhu, Q.N.; Wang, Q.; Hu, Y.B.; Abliz, X. Practical determination of the solubility parameters of 1-alkyl-3-methylimidazolium bromide ([CnClim] Br, $n=5,6,7,8)$ ionic liquids by inverse gas chromatography and the Hansen solubility parameter. Molecules 2019, 24, 1346. [CrossRef] [PubMed]

25. Alanazi, A.; Alshehri, S.; Altamimi, M.; Shakeel, F. Solubility determination and three dimensional Hansen solubility parameters of gefitinib in different organic solvents: Experimental and computational approaches. J. Mol. Liq. 2020, 299, E112211. [CrossRef] 
26. Kalam, M.A.; Alshamsan, A.; Alkholief, M.; Alsarra, I.A.; Ali, R.; Haq, N.; Anwer, M.K.; Shakeel, F. Solubility measurement and various solubility parameters of glipizide in different neat solvents. ACS Omega 2020, 5, 1708-1716. [CrossRef]

27. Anwer, M.K.; Muqtader, M.; Iqbal, M.; Ali, R.; Almutairy, B.K.; Alshetaili, A.; Alshahrani, S.M.; Aldawsari, M.F.; Alalaiwe, A.; Shakeel, F. Estimating the solubility, solution thermodynamics, and molecular interactions of aliskiren hemifumarate in alkyl imidazolium based ionic liquids. Molecules 2019, $24,2807$. [CrossRef] [PubMed]

28. Wan, Y.; He, H.; Huang, Z.; Zhang, P.; Sha, J.; Li, T.; Ren, B. Solubility, thermodynamic modeling and Hansen solubility parameter of 5-norbornene-2,3-dicarboximide in three binary solvents (methanol, ethanol, ethyl acetate + DMF) from $278.15 \mathrm{~K}$ to 323.15 K. J. Mol. Liq. 2020, 300, E112097. [CrossRef]

29. Ruidiaz, M.A.; Delgado, D.R.; Martínez, F.; Marcus, Y. Solubility and preferential solvation of indomethacin in 1,4-dioxane + water solvent mixtures. Fluid Phase Equilib. 2010, 299, 259-265. [CrossRef]

30. Hildebrand, J.H.; Prausnitz, J.M.; Scott, R.L. Regular and Related Solutions; Van Nostrand Reinhold: New York, NY, USA, 1970.

31. Manrique, Y.J.; Pacheco, D.P.; Martínez, F. Thermodynamics of mixing and solvation of ibuprofen and naproxen in propylene glycol + water cosolvent mixtures. J. Sol. Chem. 2008, 37, 165-181. [CrossRef]

32. Holguín, A.R.; Rodríguez, G.A.; Cristancho, D.M.; Delgado, D.R.; Martínez, F. Solution thermodynamics of indomethacin in propylene glycol + water mixtures. Fluid Phase Equilib. 2012, 314, 134-139. [CrossRef]

33. Krug, R.R.; Hunter, W.G.; Grieger, R.A. Enthalpy-entropy compensation. 2. Separation of the chemical from the statistic effect. J. Phys. Chem. 1976, 80, 2341-2351. [CrossRef]

34. Shakeel, F.; Haq, N.; Alsarra, I.A.; Alshehri, S. Solubility, Hansen solubility parameters and thermodynamic behavior of emtricitabine in various (polyethylene glycol-400 + water) mixtures: Computational modeling and thermodynamics. Molecules 2020, 25, 1559. [CrossRef]

35. Apelblat, A.; Manzurola, E. Solubilities of o-acetylsalicylic, 4-aminosalicylic, 3,5-dinitrosalicylic and p-toluic acid and magnesium-DL-aspartate in water from T = (278-348) K. J. Chem. Thermodyn. 1999, 31, 85-91. [CrossRef]

36. Manzurola, E.; Apelblat, A. Solubilities of L-glutamic acid, 3-nitrobenzoic acid, acetylsalicylic, p-toluic acid, calcium-L-lactate, calcium gluconate, magnesium-DL-aspartate, and magnesium-L-lactate in water. J. Chem. Thermodyn. 2002, 34, 1127-1136. [CrossRef]

37. Yalkowsky, S.H.; Roseman, T.J. Solubilization of Drugs by Cosolvents; Yalkowsky, S.H., Ed.; Techniques of Solubilization of Drugs; Marcel Dekker Inc.: New York, NY, USA, 1981; pp. 91-134.

38. Sotomayor, R.G.; Holguín, A.R.; Romdhani, A.; Martínez, F.; Jouyban, A. Solution thermodynamics of piroxicam in some ethanol + water mixtures and correlation with the Jouyban-Acree Model. J. Sol. Chem. 2013, 42, 358-371. [CrossRef]

39. Jouyban, A. Review of the cosolvency models for predicting solubility of drugs in water-cosolvent mixtures. J. Pharm. Pharm. Sci. 2008, 11, 32-58. [CrossRef]

40. Sardari, F.; Jouyban, A. Solubility of nifedipine in ethanol + water and propylene glycol + water mixtures at 293.2 to 313.2 K. Ind. Eng. Chem. Res. 2013, 52, 14353-14358. [CrossRef]

41. Khoubnasabjafari, M.; Shayanfar, A.; Martínez, F.; Acree, W.E., Jr.; Jouyban, A. Generally trained models to predict solubility of drugs in carbitol + water mixtures at various temperatures. J. Mol. Liq. 2016, 219, 435-438. [CrossRef]

42. Nozohouri, S.; Shayanfar, A.; Cardenas, Z.J.; Martinez, F.; Jouyban, A. Solubility of celecoxib in N-methyl-2pyrrolidone + water mixtures at various temperatures: Experimental data and thermodynamic analysis. Korean J. Chem. Eng. 2017, 34, 1435-1443. [CrossRef]

43. Vay, K.; Scheler, S.; Frieß, W. Application of Hansen solubility parameters for understanding and prediction of drug distribution in microspheres. Int. J. Pharm. 2011, 416, 202-209. [CrossRef]

(C) 2020 by the authors. Licensee MDPI, Basel, Switzerland. This article is an open access article distributed under the terms and conditions of the Creative Commons Attribution (CC BY) license (http://creativecommons.org/licenses/by/4.0/). 